\title{
Retzian-(La), a new mineral from Sterling Hill, Sussex County, New Jersey
}

\author{
Pete J. Dunn \\ Department of Mineral Sciences, Smithsonian Institution, Washington, DC 20560 \\ Donald R. Peacor \\ Department of Geological Sciences, University of Michigan, Ann Arbor, Michigan 48109 \\ AND \\ William B. Simmons \\ Department of Earth Sciences, University of New Orleans, New Orleans, Louisiana 70148
}

\begin{abstract}
A BStRACT. Retzian-(La), ideally, $\mathrm{Mn}_{2} \mathrm{La}\left(\mathrm{AsO}_{4}\right)(\mathrm{OH})_{4}$, is a new rare-earth analogue of retzian and retzian- $(\mathrm{Nd})$. It was found associated with willemite, calcite, and franklinite, in the Sterling Hill Mine, Ogdensburg, Sussex County, New Jersey, USA. Retzian-(La) is orthorhombic, space group Pban, with $a=5.670(7), b=12.01(1)$, and $c=4.869(8) \AA$. The strongest lines in the X-ray powder diffraction pattern are $\left(d, I / I_{0}, h k l\right): 3.5180111,2.715100$ $131,1.84850061,1.45640$. Microprobe analysis yielded $\mathrm{MnO} 25.2, \mathrm{MgO} 3.7, \mathrm{ZnO} 1.2, \mathrm{As}_{2} \mathrm{O}_{5} 26.5, \mathrm{La}_{2} \mathrm{O}_{3}$ 10.6, $\mathrm{Ce}_{2} \mathrm{O}_{3} 8.8, \mathrm{Nd}_{2} \mathrm{O}_{3} 8.2, \mathrm{Pr}_{2} \mathrm{O}_{3} 5.1, \mathrm{Sm}_{2} \mathrm{O}_{3} 2.2, \mathrm{Y}_{2} \mathrm{O}_{3} 2.5$, $\mathrm{H}_{2} \mathrm{O}$ [7.7], sum $=101.7$ wt. $\%$, corresponding to an La-dominant member of the retzian series.

Retzian-(La) forms $0.5 \mathrm{~mm}$ euhedral crystals composed of the forms $\{001\},\{010\},\{110\}$, and $\{150\}$; the crystals have pseudohexagonal habit. It is reddish-brown, with vitreous luster, no cleavage, density $>4.2 \mathrm{~g} / \mathrm{cm}^{3}$. Optically, it is biaxial, positive, $2 \mathrm{~V}=82^{\circ}$, with $\alpha=1.766$, $\beta=1.773$, and $\gamma=1.788$. Dispersion is strong, $r>v$; pleochroism is very weak; orientation is $X=c, Y=b$, $Z=a$; absorption is $Z>Y>X$.
\end{abstract}

I N early 1983 some euhedral reddish-brown crystals were found in the Sterling Hill Mine and called to the attention of the authors by John Kolic, a miner at Sterling Hill. Examination by X-ray powder diffraction techniques indicated that the crystals were in the retzian family of minerals, and a preliminary microprobe scan indicated that they were La-rich and thus a new mineral, the Laanalogue of retzian, $\mathrm{Mn}_{2} \mathrm{Ce}\left(\mathrm{AsO}_{4}\right)(\mathrm{OH})_{4}$, and retzian-(Nd), $\mathrm{Mn}_{2} \mathrm{Nd}\left(\mathrm{AsO}_{4}\right)(\mathrm{OH})_{4}$ (Dunn and Sturman, 1982). We have named this new species retzian-(La) in accordance with Levinson's rules for the naming of rare-earth analogues of known species (Levinson, 1966). The species and the name were approved by the Commission on New Minerals and Mineral Names, IMA. Type material

(C) Copyright the Mineralogical Society is preserved in the Smithsonian Institution, under catalogue No. NMNH 160290, and in the collection of Mr John Kolic.

Chemical composition. Retzian-(La) was chemically analysed using an ARL-SEMQ electron microprobe with an operating voltage of $15 \mathrm{kV}$ and a sample current of $0.025 \mu \mathrm{A}$, measured on brass. A wavelength-dispersive microprobe scan indicated the absence of any elements with atomic number greater than 8 , except those reported herein. The standards used were manganite $(\mathrm{Mn})$, hornblende $(\mathrm{Mg})$, synthetic $\mathrm{ZnO}(\mathrm{Zn})$, synthetic olivenite (As), and the rare-earth synthetic glass standards of Drake and Weill (1972) for rare earths. $L \alpha$ lines were used in the rare-earth analyses and special attention was given to possible interferences and background effects. The data were corrected using a modified version of the $M A G I C-4$ computer program. Water could not be directly determined due to paucity of material. We have calculated it from the theoretical composition of retzian-(La) and this calculation is supported by the known crystal structure (Moore, 1967). The resultant analysis yields $\mathrm{MnO} 25.2, \mathrm{MgO} 3.7, \mathrm{ZnO} 1.2, \mathrm{As}_{2} \mathrm{O}_{5} 26.5$, $\mathrm{La}_{2} \mathrm{O}_{3}$ 10.6, $\mathrm{Ce}_{2} \mathrm{O}_{3}$ 8.8, $\mathrm{Nd}_{2} \mathrm{O}_{3}$ 8.2, $\mathrm{Pr}_{2} \mathrm{O}_{3}$ 5.1, $\mathrm{Sm}_{2} \mathrm{O}_{3}$ 2.2, $\mathrm{Y}_{2} \mathrm{O}_{3} 2.5, \mathrm{H}_{2} \mathrm{O}$ [7.7], sum $=101.7$ wt. $\%$. The estimated accuracy of the analytical data is $\pm 5 \%$ of the amount present for $R E E$, and $\pm 3 \%$ of the amount present for other elements. These data yield a chemical formula, calculated on the basis of divalent cations $=2$, of:

$$
\begin{aligned}
& \left(\mathrm{Mn}_{1.54} \mathrm{Mg}_{0.40} \mathrm{Zn}_{0.06}\right)_{\Sigma 2.00} \\
& \quad\left(\mathrm{La}_{0.28} \mathrm{Ce}_{0.23} \mathrm{Nd}_{0.21} \mathrm{Pr}_{0.13} \mathrm{Y}_{0.10} \mathrm{Sm}_{0.05}\right)_{\Sigma_{1.00}} \\
& \mathrm{As}_{1.00} \mathrm{O}_{4.15}(\mathrm{OH})_{3.70}
\end{aligned}
$$$$
\text { or ideally, } \mathrm{Mn}_{2} \mathrm{La}\left(\mathrm{AsO}_{4}\right)(\mathrm{OH})_{4} \text {, with } \mathrm{Z}=2 \text {. }
$$ 
Crystallography. Precession and Weissenberg single-crystal X-ray diffraction studies showed that retzian-(La) is orthorhombic with space group $P b a n$. Lattice parameters were determined by refinement of powder diffraction data and are $a=$ 5.670(7), $b=12.01(1)$, and $c=4.869(8) \AA$. These data are in agreement with the equivalent values for retzian (Moore, 1967) and the values for retzian(Nd) (Dunn and Sturman, 1982), and imply that these three phases are isostructural. Similarities in all other data, including the powder X-ray diffraction data, confirm that relation. The powder diffraction data are listed in Table I. They were

TABLE I. X-ray powder diffraction data for retzian- $(L a)$

\begin{tabular}{rlllrl}
\hline$I / I_{0}$ & $d_{\text {meas }}$ & $d_{\text {calc }}$ & $h k l$ & $I / I_{0}$ & $d_{\text {meas }}$ \\
\hline 30 & 5.98 & 6.01 & 020 & 5 & 1.560 \\
30 & 4.84 & 4.87 & 001 & 2 & 1.552 \\
80 & 3.51 & 3.53 & 111 & 40 & 1.456 \\
5 & 3.26 & 3.27 & 130 & 5 & 1.425 \\
10 & 3.01 & 3.00 & 040 & 5 & 1.285 \\
20 & 2.835 & 2.835 & 200 & 2 & 1.260 \\
100 & 2.715 & 2.715 & 131 & 10 & 1.231 \\
10 & 2.562 & 2.564 & 220 & 5 & 1.180 \\
& & 2.566 & 041 & 10 & 1.159 \\
10 & 2.445 & 2.450 & 201 & 2 & 1.083 \\
5 & 2.332 & 2.330 & 141 & 5 & 1.069 \\
2 & 2.260 & 2.269 & 221 & & \\
& & 2.256 & 022 & & \\
20 & 2.064 & 2.061 & 240 & & \\
20 & 2.014 & 2.014 & 151 & & \\
10 & 1.955 & 1.953 & 132 & & \\
10 & 1.895 & 1.898 & 241 & & \\
& & 1.891 & 042 & & \\
50 & 1.848 & 1.852 & 061 & & \\
& & 1.847 & 202 & & \\
2 & 1.769 & 1.765 & 222 & & \\
2 & 1.744 & 1.743 & 311 & & \\
5 & 1.714 & 1.715 & 251 & & \\
30 & 1.615 & 1.613 & 331 & & \\
10 & 1.579 & 1.573 & 242 & & \\
\hline
\end{tabular}

obtained using an $114.6 \mathrm{~mm}$ diameter Gandolfi camera, $\mathrm{Si}$ as an internal standard, $\mathrm{Cu}-K \alpha$ radiation, and a polycrystalline mount. Intensities are visually estimated.

The crystal used for single-crystal X-ray diffraction was also used as a source for optical goniometric data. The faces were indexed as a large pinacoid $\{001\}$, prism $\{110\}$, pinacoid $\{010\}$, and prism $\{150\}$; faces of the latter form are very small. A typical crystal is represented in clinographic projection in fig. 1. Most crystals have a pseudohexagonal appearance, defined largely by the six faces consisting of the prism $\{110\}$, and pinacoid $\{010\}$. The faces of the latter form may be bright and shiny as opposed to the dull lustre of the other forms.

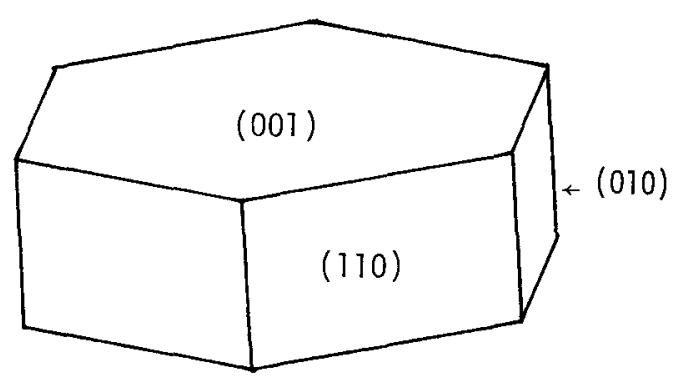

FIG. 1. Clinographic projection of pseudohexagonal habit of retzian-(La).

Physical and optical properties. Retzian-(La) is dark reddish-brown in colour with a light-brown streak. The lustre is vitreous and the mineral is transparent. The hardness (Mohs) is approximately 3-4. The density, measured using heavy-liquid techniques, is greater than $4.2 \mathrm{~g} / \mathrm{cm}^{3}$, compared with the calculated value of $4.49 \mathrm{~g} / \mathrm{cm}^{3}$. Cleavage was not observed; the fracture is even. Retzian-(La) is not fluorescent in ultraviolet radiation.

Optically, retzian-(La) is biaxial, positive, $2 \mathrm{~V}=$ $82(9)^{\circ}$ (meas.), $69^{\circ}$ (calc.). The indices of refraction, measured in sodium light, are $\alpha=1.766(5), \beta=$ $1.773(5)$, and $\gamma=1.788(5)$. Dispersion is strong, $r>v$; the orientation is $X=c, Y=b, Z=a$. Pleochroism is very weak, varying from pale brown to pale violet-brown. Although the pleochroism is very patchy, we encountered no measurable chemical differences in the crystals analysed. Absorption is $Z>Y>X$.

Occurrence. Retzian-(La) was found on one specimen in the Sterling Hill Mine, Ogdensburg, Sussex County, New Jersey. It occurs as very small (0.1-0.5 mm) euhedral crystals on an altered fracture surface in highly calcic willemite-franklinite ore. The ore surface is stained black by todorokite (verified by XRD). Retzian-(La) is among the last phases to form; willemite, in acicular crystals, may be contemporaneous in formation.

Acknowledgements. We thank Mr John Kolic for calling these crystals to our attention. Many of the recent discoveries at Sterling Hill have resulted from his observations. This study was supported, in part, by a grant from 
Mrs E. Hadley Stuart, Jr. P.J.D. acknowledges the continued assistance of the Trustees of the Franklin Mineral Museum.

\section{REFERENCES}

Drake, M. J., and Weill, D. F. (1972) Chem. Geol. 10, 179-81.
Dunn, P. J., and Sturman, B. D. (1982) Am. Mineral. 67, $841-5$.

Levinson, A. A. (1966) Ibid. 51, 152-8.

Moore, P. B. (1967) Ibid. 52, 1603-13.

[Manuscript received 20 January 1984] 